\title{
Realization of the energy strategy of the Russian Federation regarding the transportation of energy resources
}

\author{
Elizaveta Zotova ${ }^{1, *}$, Alexey Tebekin $^{2}$, Oleg Yastrebov $^{3}$, and Borremans Alexandra ${ }^{1}$ \\ ${ }^{1}$ Peter the Great St. Petersburg Politechnic Univetsity (SPbPU), 29 Politechnicheskaya St, 195251 \\ Russian Federation \\ ${ }^{2}$ Moscow State Institute of International Relations (University). Neo-Sport Str., Moskovskaya oblast, \\ Odintsovo, 143007 Russian Federation \\ ${ }^{3}$ Peoples Friendship University of Russia (RUDN University), 6 Miklukho-Maklaya St, Moscow, \\ 117198, Russian Federation
}

\begin{abstract}
The current problems and prospects for the development of the world market of energy resources are considered. On the basis of the "Energy Strategy of Russia for the period until 2030" the prospects for its implementation in terms of the transportation of energy resources were determined from the standpoint of the supply strategy model (procurement) using the P. Kralich matrix (highlighting the strategic, basic, non-critical and problematic energy resources transported); from the standpoint of the traditional SWOT-analysis (with the allocation of external market opportunities, external threats, internal strengths and internal weaknesses that hinder the increase in the efficiency of energy use during transportation).
\end{abstract}

\section{Introduction}

The modern world economy is on the verge of another economic crisis, which is expected, according to copyright research [1], in the early 2020s.

It is highly likely that this crisis will be much larger than the previous global economic crisis of 2008-2009 [2].

If the world economic crisis of 2008-2009 had a speculative financial nature [3], then the expected world economic crisis of the 2020s will be associated with an objective transition from the fifth technological order to the sixth [4], in which the contradictions between the level of development of productive forces and the nature of the existing production relations [5].

It is expected that the basis of the global economic crisis of the 2020s, as well as the basis of the previous world economic crisis in the framework of large cycles of economic activity that occurred during the change of the fourth technological order by the fifth in the early 1970s [6] will be a shortage of energy resources [7].

\footnotetext{
* Corresponding author: zotova@kafedrapik.ru
} 
It is not by chance that among the expected basic advantages of the sixth technological order based on nanotechnology and cellular technologies [8], along with the creation of materials and organisms with predetermined properties and a significant reduction in material intensity, there is a sharp decrease in energy intensity.

According to one of the likely scenarios, the solution of the energy problem during the transition from the fifth technological order to the sixth one can lead to the fact that hydrocarbons will no longer be a key source of energy [9].

On the other hand, a huge increase in the interest of global market participants to hydrocarbon sources in the Arctic [10] indicates that it is possible that the leadership of hydrocarbons in the energy resource market will continue after the crisis of 2020s.

In any case, the shift of the peak of K. Hubbert's curve in time to the right (Fig. 1) [11], due to hydrocarbon reserves in the Arctic, constituting about $50 \%$ of the currently proven reserves of world deposits, favors the scenario of maintaining the leadership of hydrocarbons in the global energy market.

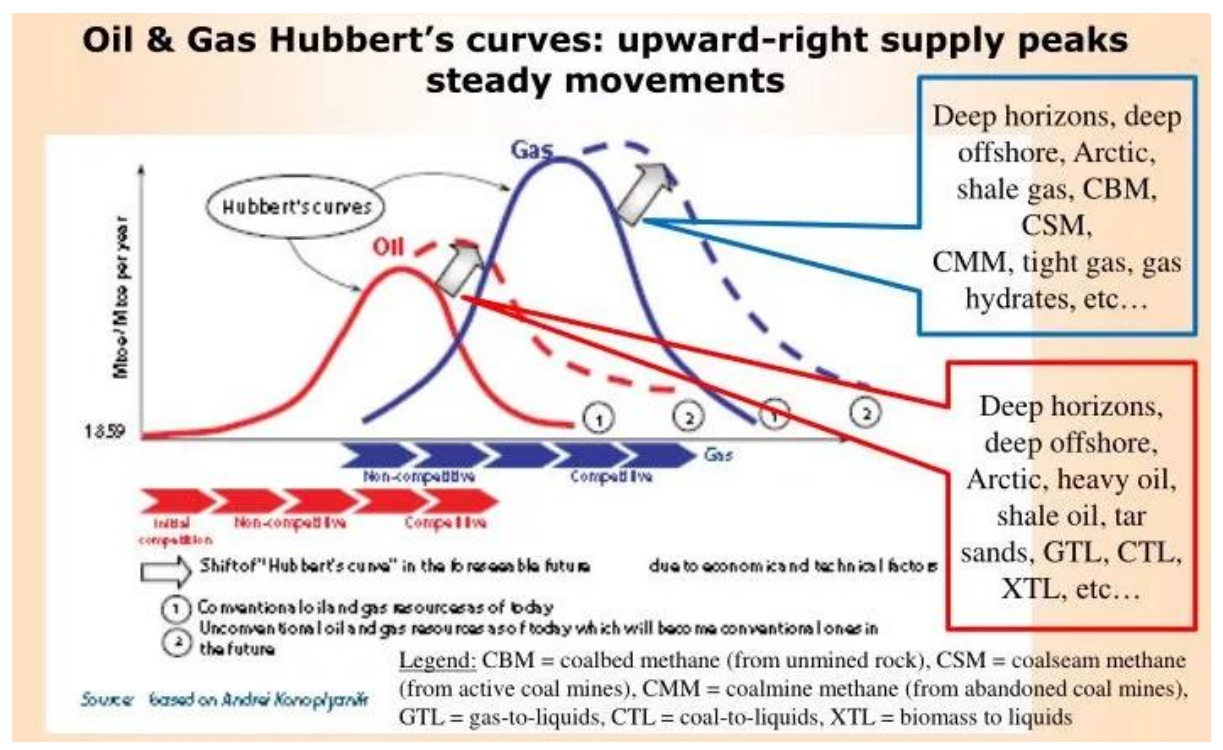

Fig. 1. The temporal dynamics of the hydrocarbon market in the economic interpretation of the K. Hubbert curve shift.

\section{Results}

For the Russian Federation, the problem of energy efficiency is historically one of the key.

The plans to solve this problem, formed in the framework of Kosygin-Lieberman's reforms [12] as early as the $1960 \mathrm{~s}$, that is, well in advance of the global economic crisis of the 1970 s, unfortunately, were not destined to become realized.

The plans for the intensification of the processes of economic development proposed in this reform [13], including in the energy sector, have unfortunately been rejected.

Given the current state of the international division of labor, it should be noted that the problems of energy efficiency have not become less relevant for Russia.

And considering that the Russian Federation is the largest state in the world in terms of the size of the territory, the solution of energy problems in the transport sector for Russia is the most urgent. 
According to expert estimates, only the untapped potential of organizational and technological energy saving in the transport sector ranges from $20 \%$ to $30 \%$.

At present, the directions of the energy strategy of the Russian Federation in the transport sector are determined, on the one hand, by the "Energy Strategy of Russia for the period until 2030" [14], and, on the other hand, by the "Transport Strategy of the Russian Federation for the period until 2030" [15].

In this review, the directions of the energy strategy of the Russian Federation in the transport sector are analyzed from the standpoint of the "Energy Strategy of Russia for the Period until 2030" [14].

According to the "Energy Strategy of Russia for the period up to 2030" [14], the development of the national economy under the basic innovation scenario is characterized, among other things, by the full-scale provision of intensive development of the transport and energy infrastructure ensuring the effective integration of Russia into the Euro-Asian economic space.

At the same time, a qualitative change in the role of the fuel and energy complex in the development of the national economy is strategically incorporated. The Energy Strategy of Russia for the Period until 2030 [14] stipulates that the Russian energy sector, historically the largest customer for many related industries and the economy (including transport), will also become an investor in the innovative development of the domestic economy, including ensuring the growth of energy efficiency in the transport sector.

The "Energy Strategy of Russia for the Period until 2030" [14] also laid down that Russia, as a country with a unique gas transmission system that ensures gas supplies to Europe and the countries of the Commonwealth of Independent States, will continue to move along the path of developing and increasing the efficiency of this transport system.

In the interests of increasing the efficiency of energy transportation systems and improving their safety, the Energy Strategy of Russia for the Period until 2030 [14] provides for the regulation of the minimum allowable reserves of generating and energy transportation capacities.

In the interest of increasing reliability and reducing logistical costs in the use of energy transmission capacities, which ensure a reduction in the production and sales cycle, the Russian energy strategy for the period up to 2030 includes [14]:

- ensuring reliable operation and predictable development of the energy infrastructure;

- gradual lifting of restrictions in the transportation of energy resources both between different regions of the country and between separate territorial production complexes (energy hubs) within regions.

It should be noted that such a strategic decision is fully consistent with global logistics trends [19].

Of course, the creation of a favorable economic environment for the development of the transport sector in the Russian Federation is significantly influenced by state price (tariff) regulation, which, on the one hand, takes into account an objective increase in the costs of extraction, production and transportation of energy in the domestic market. But, on the other hand, it needs to be improved, since in recent years the realized and pledged rate of growth of excise taxes on fuel in Russia has significantly exceeded the growth rate of GDP over the same period (Fig. 2). 


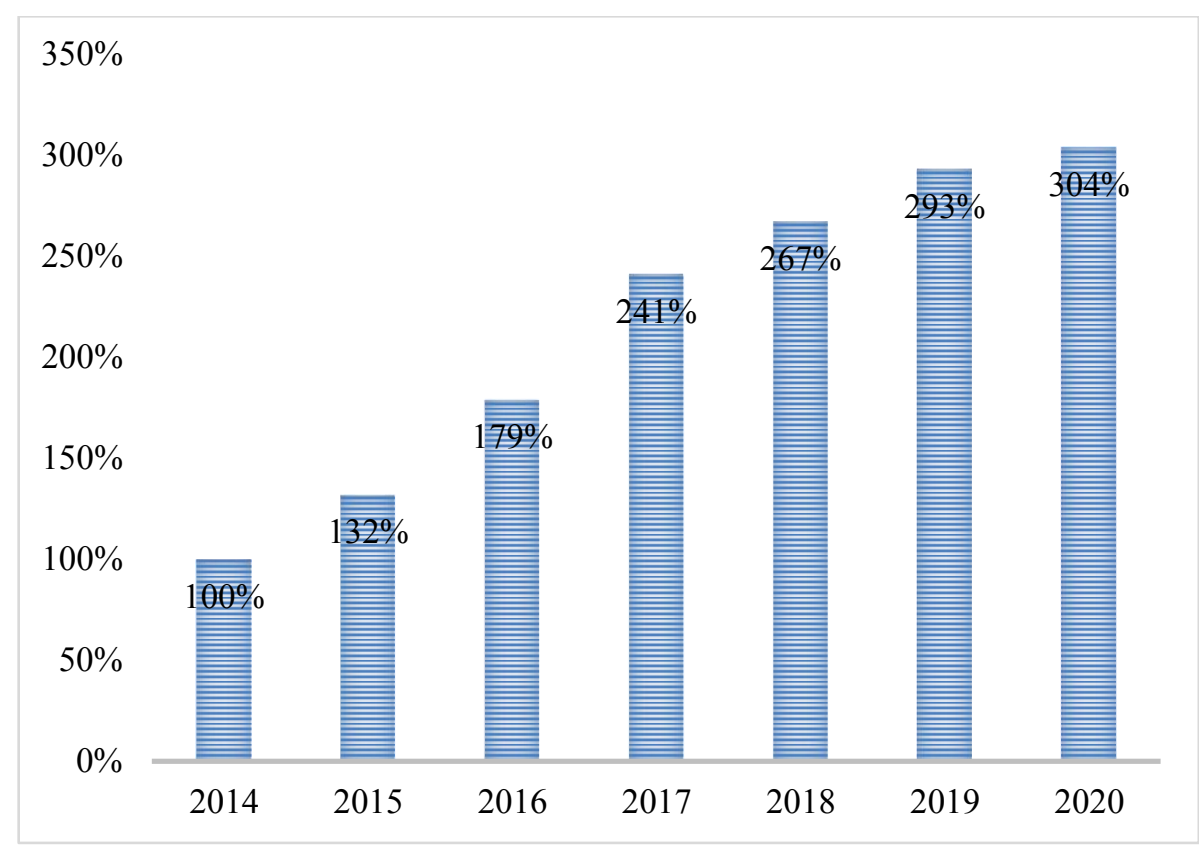

Fig. 2. Dynamics of excise taxes on fuel (gasoline class 5) from 2014 to 2020.

The most important component of the energy strategy of the Russian Federation in the transport sector, laid down in the "Energy Strategy of Russia for the period until 2030" is to ensure the environmental safety of the Russian energy sector, which minimizes the negative impact of production, production, transportation and consumption of energy on the environment and climate [14].

The environmental vector of the energy strategy of the Russian Federation in the transport sector is associated with the creation of a favorable economic environment that stimulates the creation of conditions for the introduction of environmentally friendly energy-efficient and resource-saving technologies in the production, transportation, storage and use of fuel and energy resources [14].

When implementing the regional energy policy "Energy Strategy of Russia for the period until 2030", it is planned to develop the necessary interregional and regional energy transportation communications, create different types of energy infrastructure for regional territorial production clusters of energy-intensive (resource) and energy-efficient (innovative) development types [14].

As part of the implementation of the innovation and scientific-technical policy in the energy sector, the Energy Strategy of Russia for the period until 2030 provides for the practical implementation of the developed technological and experimental design solutions in part [14]:

- installations of energy and transport purpose, working on alternative fuel;

- power plants on fuel cells (solid polymer and solid oxide) for autonomous, backup, emergency power engineering and vehicles;

- equipment for production, transportation and storage of standardized coal fuel;

- high-performance mining and transport equipment of continuous and cyclic action, including for selective mining of coal seams, ensuring the development of underground coal mining technology with the predominant use of cleaning mechanized complexes and new-level tunneling equipment, as well as short-haul down-hole technology using continuous combine harvesters and self-propelled means of transportation coal 
As part of the implementation of the external energy policy, the Energy Strategy of Russia for the period until 2030 provides for stimulating the construction of transport infrastructure to diversify sales markets and export directions of Russian energy resources in the east, south, northwest and north of the country [14].

It should be noted that the implementation of this component of the energy strategies of the Russian Federation in the transport sector has problems caused by the inertia of the implementation of decisions that have long been matured in the field of energy transportation [16].

Among the strategic initiatives for the development of the fuel and energy complex in the "Energy Strategy of Russia for the Period until 2030", there are [14]:

- the formation of oil and gas complexes in the eastern regions of the country (the continental shelf of Sakhalin Island, the Republic of Sakha (Yakutia), Magadan, Irkutsk Regions and the Krasnoyarsk Territory) with the development of appropriate production, transport and social infrastructure will not only provide these regions with their own energy resources, but also diversify export deliveries of Russian hydrocarbons, sending them to the countries of the Asia-Pacific region;

- integrated development of territories on the Yamal Peninsula, on offshore gas fields on the continental shelf of the Barents, Pechora and Kara Seas with the creation of an appropriate infrastructure of marine and pipeline transport will contribute to the development of industries related to the creation of modern technical means and technologies for prospecting, exploration, production and transportation of oil and gas on the continental shelf of the Russian Federation, as well as the development of the Northern Sea Route;

- construction of a multi-line gas transmission system from the Yamal Peninsula; development of port and transport infrastructure for the transport of liquid hydrocarbons (oil, condensate, liquefied natural gas, a broad fraction of light hydrocarbons);

- improving the efficiency of using the established port capacity for transshipment and sea transportation of liquid hydrocarbons in the town of Primorsk and the village of Varandey;

To achieve the strategic goals of the development of the oil complex in the "Energy Strategy of Russia for the period until 2030", the need is noted [14]:

- development of transport infrastructure, including pipeline, to improve efficiency, diversify the structure and directions of transportation of oil and oil products;

- development of technologies for resource and energy saving, reduction of losses at all stages of the technological process in the preparation of reserves, production, transportation and processing of oil.

In addition, the Energy Strategy of Russia for the Period up to 2030 notes that [14]: to create a favorable economic environment, it is necessary to form the necessary legislative support for the priority right of access to free gas transmission networks of suppliers of its processed product - dry (lean) gas.

In general, the development of pipeline transportation of oil and oil products should be carried out adequately to the growth of volumes and diversification of external and internal supplies of liquid hydrocarbons. The Energy Strategy of Russia for the Period until 2030 also [14] addresses the challenges of further increasing the share of pipeline transportation of liquid hydrocarbons in the total volume of transportation of oil and especially oil products, ensuring conditions for the formation of new oil-producing regions of the country, ensuring a balance between the required volumes of oil the carrying capacity of the transport system, as well as reducing Russia's dependence on the transit of oil and oil products through the territories of States.

The main projects in the development of pipeline transportation of oil and petroleum products in the "Energy Strategy of Russia for the period until 2030" are defined [14]: 
- completion of the construction of the Eastern Siberia-Pacific Ocean oil pipeline with a throughput capacity of 80 million tons of oil per year;

- construction of the Unecha-Ust-Luga oil pipeline (second line of the Baltic pipeline system);

- development of export oil and oil products terminals in the ports of Primorsk, UstLuga, Nakhodka;

- development of the country's oil product pipeline system (bringing the North product pipeline to the design capacity, construction of the Andreyevka-Ufa-SubkhankulovoAlmetyevsk-Kstovo oil product pipeline, construction of the Yug oil product pipeline).

It is envisaged that in addition to pipeline transportation of oil and petroleum products, marine transportation of liquid hydrocarbons, including from the coastal areas of the Russian part of the Arctic, will also be developed.

Much attention in the "Energy Strategy of Russia for the period up to 2030" is paid to a high degree of competition due to, including through [14]:

- determining the procedure for non-discriminatory access to the transport infrastructure;

- exclusion of excessive administrative barriers in the performance of work on the exploration, production, storage and transportation of oil, as well as in obtaining permits for the construction of gas stations and the allocation of land for such construction.

In terms of solving problems, energy saving in the oil complex in the "Energy Strategy of Russia for the period until 2030" provides [14] for oil transportation - reconstruction of oil pipeline facilities and system organization of their technological modes, reduction of oil losses, introduction of automated control systems and remote control, improvement technical condition of oil pumping units, as well as the widespread introduction of floating roof tanks.

In addition, it is noted that the development of the export infrastructure for the transport of oil will allow Russia to diversify its export supplies and reduce transit risks in the western direction. At the same time, the tendency towards stabilization of oil export volumes will stimulate the expansion of the use of the Russian oil transport infrastructure (pipelines, sea terminals) to ensure transit supplies.

At the same time, among the main problems in the gas industry are:

- availability of infrastructural restrictions in the field of pipeline gas transportation;

- high transit risks of gas exports to Europe;

- insufficient level of development of the gas processing and gas chemical industry.

In addition, for the utilization and transportation of fat gas and condensate, a wide development of the gas processing industry is envisaged.

Along with pipeline transportation of gas in Russia, the Energy Strategy of Russia for the Period until 2030 provides [14] active implementation of projects in the production and transportation of liquefied natural gas, primarily to strengthen the export position of the Russian Federation in the external market.

The Energy Strategy of Russia for the Period until 2030 [14] indicates that the combination of supplies of liquefied natural gas with a well-developed gas transportation infrastructure will give a powerful impetus to increase the efficiency of gas exports while simultaneously diversifying markets.

Russia's energy strategy for the period until 2030" provides [14] that the functioning of the gas production and sales sectors based on market relations while maintaining state regulation in the field of gas transportation, on the one hand, will ensure non-discriminatory access of market entities to gas transmission systems of different levels, On the other hand, it will provide the same specific tariffs for gas transportation.

Among the internal problems implemented according to the "Energy Strategy of Russia for the period until 2030" [14], the problem of gasification of regions is highlighted, 
including work on expanding the eastern gas transmission system with possible connection to the unified gas supply system in case of economic efficiency.

It is not by chance that President of the Russian Federation Vladimir Putin, at a meeting with the head of Gazprom, Alexey Miller, ordered to prepare proposals for accelerating the gasification of the country [17].

As regards the achievement of the strategic goals of the development of the coal industry, the "Energy Strategy of Russia for the Period until 2030" provides for [14]:

- continued development of transport and port infrastructure for the transport of coal cargo at economically reasonable tariffs, ensuring diversification of the directions of their supply;

- the application of flexible tariff regulation schemes for the transport of coal by rail;

- formation of a leasing company, providing the provision of high-tech mining, mining and processing equipment;

- removal of system restrictions during the transportation of coal cargo to the domestic and foreign markets.

As part of the power industry, the Energy Strategy of Russia for the period until 2030 provides for [14]:

- investment and innovative renewal of the industry, aimed at ensuring high energy, economic and environmental efficiency of production, transportation, distribution and use of electricity;

- creation of intersystem power lines of alternating and direct current for transportation of electric energy and power from energy-efficient to energy-deficient regions in volumes not exceeding the reliability requirements of the Unified Energy System of Russia;

- reducing losses in electrical networks and improving the efficiency of electricity transportation, including through the widespread introduction of conductors from new composite materials, which increase the current carrying capacity and increase the duration of their service life, as well as the creation of automated metering and control systems in electrical networks;

- a significant increase in the energy efficiency of the industry, including by reducing the specific fuel consumption for the supply of electricity and thermal energy from thermal power plants, as well as by reducing losses (energy transport costs) in electrical networks. [14]:

In terms of heat supply, Russia's Energy Strategy for the Period until 2030 provides for

- development of a regulatory legal framework that ensures effective interaction between heat producers, organizations involved in its transportation and distribution, as well as consumers in the market conditions of the industry;

- reduction of heat losses and coolant leakage as a result of reconstruction of heating networks based on the use of heat pipes of factory readiness, effective methods of their installation, modern shut-off and control devices, automated nodes and mode management systems, as well as the organization of optimal operation modes of heat networks, heat sources and consumers;

- raising the standards for providing heat supply services as a result of optimizing the structure of systems, the ratio of centralized and decentralized heat supply, improving reliability, safety, energy and economic efficiency of production, transportation and heat consumption by upgrading fixed production assets and heating networks, as well as providing consumers with accounting systems and regulation. It should be noted that one of the key areas of the energy strategy of the Russian Federation in the transport sector, according to the "Energy Strategy of Russia for the period until 2030" [14], is to ensure a rational, economically reasonable growth in the use of various types of renewable energy sources for the production of electric and thermal energy, and expanding the use of alternative fuels for transport and energy. 
If we consider the energy strategy of the Russian Federation in terms of the transportation of energy resources from the standpoint of the supply strategy strategy (procurement) using the P. Kralich matrix [18], then:

- gas is released as a strategic energy source;

- oil is emitted as the base energy transported;

- as non-critical transported energy resources, electricity and thermal energy are released;

- coal is released as the problem energy transported.

If we consider the energy strategies of the Russian Federation in terms of the transportation of energy resources from the standpoint of the traditional SWOT analysis, then in the "Energy Strategy of Russia for the Period until 2030" [14], the following are clearly highlighted:

- external market opportunities due to world market demand for energy resources;

- external threats determined by permanent economic sanctions against Russian energy companies;

- internal force, caused, first of all, by the substantial reserves of energy resources in the Russian Federation;

- internal weaknesses determined by: insufficient development of the energy infrastructure, insufficient use of reserves to improve the efficiency of energy use during their transportation.

\section{Conclusion}

At the same time, the question of influence on the nature of energy consumption of state price (tariff) regulation, which, in our opinion, hinders the effective implementation of the energy strategy of the Russian Federation in terms of energy transportation, remains controversial.

Another objective problem of the implementation of the energy strategy of the Russian Federation in terms of the transportation of energy is the inertia of the implementation of the processes of creating transport infrastructure against the background of rapidly changing situations of spatial market demand for energy. First of all, it concerns the foreign markets that determine the problems of exporting energy resources.

\section{References}

1. A.V. Tebekin, Journal of Economic Research 4(12), 3-9 (2018)

2. A.V. Tebekin, M.V. Konotopov, Innovation and investment 1, 2-8 (2009)

3. A.V. Tebekin, M.V. Konotopov, Innovation and investment 1, 2-6 (2010)

4. A.V. Tebekin, G.N. Seryakov, Bulletin of Tver State University. Series: Economics and Management 3, 8-17 (2018)

5. A. Tebekin, Century Strategic management (Publishing house Yurayt, Moscow, 2019)

6. M.V. Konotopov, Economic history: a textbook for bachelors, 12th ed. (Publishing house Yurayt, Moscow, 2019)

7. A.V. Tebekin, Innovation 3(221), 11-17 (2017)

8. S.Yu. Glazyev, V.V. Kharitonov, Nanotechnology as a key factor in the new technological order in the economy (Trent, Moscow, 2009) 
9. A.V. Tebekin, Customs Readings - 2015. The Eurasian Economic Union in the Context of Globalization: Challenges, Risks, Trends, and a collection of materials from the AllRussian Scientific and Practical Conference, 103-106 (2015)

10. A.V. Tebekin, Journal of management studies 4(10), 55-63 (2018)

11. A. Konoplyanik, FINEC SPB 12,13 (2013)

12. E.G. Liberman, Economic Methods and the Effectiveness of Production (White Plains: International Arts and Sciences Press, 1972)

13. A.V. Tebekin, Innovation 3(221), 11-17 (2017)

14. Russia's energy strategy for the period up to 2030 (Government of the Russian Federation, 2009)

15. Transport strategy of the Russian Federation for the period up to 2030 (Government of the Russian Federation, 2008)

16. A.V. Tebekin, Nine scenarios for the strategic development of the national economy (Moscow, 2016)

17. https://tass.ru/ekonomika/6209024

18. P. Kraljic, Purchasing Must Become Supply Management (Harvard Business Review, 1983)

19. A.V. Tebekin, International Logistics, Minsk, 8-19 (2017) 